\title{
Alfabetização e letramento em língua materna e em matemática*
}

\section{Literacy in native language and mathematics}

\author{
Madeline Gurgel Barreto Maia ${ }^{1}$ • Cristina Maranhão ${ }^{2}$
}

\begin{abstract}
Resumo: Este trabalho objetiva discutir visões, perspectivas e relações entre processos de alfabetização e letramento em língua materna e em matemática, dadas as exigências brasileiras para o Ensino Fundamental de nove anos. Seguindo a abordagem da tese em que se embasa, esta é uma investigação qualitativa, de caráter teórico, sobre documentos oficiais e pesquisas do período de 1996 a 2012. Ponderamos que, considerando as características dos processos estudados, é possível abrir melhores possibilidades formativas para os estudantes no que concerne aos processos de alfabetização e letramento em matemática e língua materna. Por isso, baseadas nas posições teóricas investigadas, indicamos algumas implicações para o ensino e a formação em cada um dos processos discutidos, para destacar suas interdependências e relevâncias. Finalmente, nas conclusões, oferecemos fundamentação a escolhas de estratégias de ensino e formação, o que pode influenciar políticas institucionais de várias instâncias (escolares e governamentais, por exemplo).
\end{abstract}

Palavras-chave: Alfabetização e letramento. Língua materna. Alfabetização matemática. Estratégias de ensino. Ensino Fundamental.

Abstract: This paper addresses perspectives and connections between Native Language and Mathematics Literacies, regarding the official requirements for Brazilian nine years of 'Fundamental School', in order to emphasize their interdependence and relevance. A qualitative study based on official documents and researches from 1996 to 2012 is presented. Based on this process, it is possible to come up with some improvements in basic education, related to language and mathematical literacies. The authors suggest the impact of governmental policies for educational institutions. The theoretical background that can be used to choose a suitable mathematical education strategy for Fundamental Schools is given in the conclusion.

Keywords: Native language literacy. Mathematics literacy. Teaching strategies. Fundamental school.

\footnotetext{
*Artigo baseado em parte da tese da primeira autora.

${ }^{1}$ Departamento de Educação Básica, Centro de Educação, Universidade Federal da Paraíba (UFPb), campus I, Rua Maria Rosa Jacinto, Bessa, CEP 58035-280, João Pessoa, PB, Brasil. E-mail: <madelinemaia@yahoo.com.br> ${ }^{2}$ Departamento de Matemática, Pontifícia Universidade Católica de São Paulo (PUCSP), São Paulo, SP, Brasil.
} 


\section{Problemática}

A trajetória do Ensino Fundamental no Brasil, que foi definida, pelas novas políticas públicas voltadas à Educação, como tendo a duração de nove anos, trouxe, entre outras questões, implicações ao Ensino de Matemática nos três primeiros anos de escolaridade básica. Por determinações legais, os primeiros, segundos e terceiros anos do Ensino Fundamental passaram a compor um ciclo chamado de "Ciclo da Alfabetização", com inclusão da criança de 6 anos de idade no primeiro ano deste segmento.

A partir disso, novas exigências didáticas, metodológicas, de estruturação física da escola, de formação dos professores, de gestão etc. foram surgindo. Algumas orientações foram, desta forma, encaminhadas às escolas por meio de publicações oficiais, como, por exemplo, o documento Ensino Fundamental de 9 anos: orientações gerais (BRASIL, 2004). Resumimos esquematicamente o que depreendemos destas orientações: assegurar um processo educativo respeitoso às crianças que entram neste novo Ensino Fundamental; considerar a existência de processos diferenciados, como Alfabetização e Letramento no Ciclo da Alfabetização; a necessidade de utilização de diferentes contextos de aprendizagem e uso do conhecimento; considerar o perfil, as individualidades dos alunos; desenvolver estratégias respeitando a nova criança do Ensino Fundamental; trabalhar a Linguagem Escrita e as diferentes formas de representação do conhecimento; a importância do ambiente escolar e doméstico para o desenvolvimento da aprendizagem; trabalhar os aspectos funcionais da língua; considerar a necessidade de um tempo maior para o processo de Alfabetização.

Sobre a Alfabetização Matemática para esses anos, de acordo com o documento Ensino fundamental de nove anos: passo a passo do processo de implantação (BRASIL, 2009), a determinação do que e como se trabalhar é de competência dos sistemas de ensino. No entanto, para subsidiar a discussão, o documento considera importante observar, além de documentos específicos das escolas e dos sistemas de ensino:

a) os dispositivos legais - Constituição Federal, Lei no. 9.394/96 (LDB), Lei no. 10.172/2001 (Plano Nacional do Livro Didático), Diretrizes Curriculares Nacionais para o Ensino Fundamental, Pareceres e Resoluções do CNE e do respectivo sistema de ensino; b) as publicações e os documentos: Parâmetros Curriculares Nacionais, Ensino Fundamental de nove anos: orientações gerais para a inclusão da criança de seis anos de idade (publicação do MEC), Indagações sobre Currículo (Publicação do MEC) [...]; c) as pesquisas educacionais e produções científicas; d) a literatura pertinente. (BRASIL, 2009, p. 24)

Assim, cabe aos professores, gestores educacionais a tarefa de delinear que aspectos priorizar e como conduzi-los na Alfabetização e Letramento em Matemática.

Em face dos documentos e pesquisas que os professores e gestores educacionais teriam que se debruçar para escolhas de estratégias de ensino e formação, pareceu-nos importante este artigo oferecer embasamento sobre elas. Acreditamos que as discussões aqui apresentadas, sobre perspectivas da Alfabetização e Letramento em Matemática, podem subsidiar debates e reflexões fecundas sobre como conduzir o ensino de matemática em escolas brasileiras, em função do que se pode alcançar na formação matemática dos estudantes. 
Seguindo a abordagem da tese em que se baseia, esta é uma investigação qualitativa, de caráter teórico, sobre documentos oficiais e pesquisas do período de 1996 a 2012. Conforme a motivação deste estudo, para não ficarmos restritas ao âmbito acadêmico e, de certa forma, atingirmos, também, as escolas brasileiras, na seleção do corpus, priorizamos os documentos de fácil acesso para diferentes leitores com o máximo possível de informações válidas e pertinentes ao assunto tratado.

Por isso, buscamos documentos oficiais e pesquisas de Educação Matemática, a partir de buscas nos sítios Scielo ${ }^{3}$ e Portal de Periódicos da Capes ${ }^{4}$. Tais sítios são referências no meio escolar e acadêmico, possibilitando acesso a textos completos de documentos e de artigos científicos nacionais e internacionais.

A seleção de pesquisas se deu a partir de palavras-chave que surgiram de leituras prévias relacionadas ao objeto de estudo: alfabetização matemática, numeracia, numeramento, numerate, numeracy, matemacia, literacia matemática, materacy e materacia; aplicamos também os filtros: a partir de 1996; Educação Matemática e anos iniciais do Ensino Fundamental.

Por haver repetições de pesquisas nessa seleção, além de problemas para abrir alguns arquivos, ficamos com 12 pesquisas de Educação Matemática que poderiam fornecer referências teóricas fecundas para esta investigação. Nelas, encontramos maior frequência de embasamento teórico nos autores: Skovsmose, D’Ambrósio, Danyluk e Fonseca (nessa ordem).

No decorrer das leituras realizadas em obras desses autores, evidenciou-se a forte presença de processos concernentes à Alfabetização e Letramento em Língua Materna fundamentando os processos que aqui designamos Alfabetização e Letramento em Matemática.

Destarte, neste texto, nos propomos a apresentar e discutir o que julgamos primordial sobre visões, perspectivas e relações entre esses processos, tecendo implicações para o ensino, com a finalidade de oferecer estratégias de ensino e formação teoricamente embasadas.

\section{Visões de Alfabetização e Letramento em Língua Materna: relações}

Dentro do processo de Alfabetização em Língua Materna, percebemos a existência de duas visões: (1) a Alfabetização considerada como de caráter restrito e; (2) o Letramento, interpretado como um processo mais amplo.

Na primeira visão temos a Alfabetização em Língua Materna, que guarda a ideia de finitude, quanto ao domínio de códigos e símbolos, ao que dá-se importância capital. Logo, esta visão privilegia aspectos organizacionais e sintáticos da língua.

Nela, encontramos: Abud (1987) que a coloca como sendo primordialmente voltada ao domínio das letras; Giroux (1989) que, embora considere a existência de tal visão, a critica por acreditar que, nesta proposta, favorecem-se formas de ignorância política e ideológica; Cook-Gumperz (1991) considerando-a como, em determinadas circunstâncias, tendo papel fundamental de ascensão social; Kleiman (1995) com uma abordagem sinalizando que é possível seu ensino desvinculado do contexto; Tfouni (2004) que a entende como domínio do código

\footnotetext{
${ }^{3}$ Disponível em: <http://www.scielo.org>. Acesso em: 10 set. 2013.

${ }^{4}$ Disponível em: <http://www.periodicos.capes.gov.br>. Acesso em: 18 ago. 2013.
} 
escrito, vinculada ao desenvolvimento do raciocínio, já que esta contribui para uma melhor organização do pensamento; e, por fim, temos Goody e Watt (1997), com linhas de pensamento semelhantes às de Tfouni (2004).

Scribner e Cole (1981), ao colocarem os processos de ensino da leitura e da escrita como sendo de responsabilidade da instituição escolar, apontam para a verificação de uma oralidade desenvolvida como prática corriqueira na escola, que evidencia poderes de análise e síntese oral. Assim, o desenvolvimento do raciocínio dos alunos que frequentam a escola é favorecido. Logo, atribuem a esta lócus fundamental para a organização do pensamento e de conhecimentos incorporados da realidade. A instituição escolar assume o papel de ambiente onde os alunos expressam oralmente aquilo que aprendem e que, em um processo de ensino formal, esse conhecimento se transforma; deste modo, direta ou indiretamente, dão relevância ao trabalho e interferência do professor e aos contextos trazidos pelos alunos.

Assim sendo, a segunda vertente, o Letramento em Língua Materna, caracteriza-se como um processo mais amplo, por não se ater ao domínio de códigos e símbolos e incluir reflexões sobre significados do que se fala, lê e escreve em variados contextos com suporte cultural e social. Esse processo envolve a semântica e é influenciado por práticas sociais, tendo, portanto, natureza sócio-histórica. Nela consideram-se o meio e o contexto de produção do conhecimento, sendo, assim, importante o ambiente interno e externo à escola.

Nesta visão, encontramos Street (1984), que apresenta dois modelos interdependentes: autônomo e ideológico. No primeiro, têm-se as questões concernentes ao domínio dos códigos e símbolos; e, no segundo, os aspectos de estrutura social que envolvem práticas culturais e a preocupação com inclusão, justiça e libertação do homem; Giroux (1989), bem como Silva e Espósito (1990) apontam a necessidade de saída de modelos técnicos para um modelo em que a alfabetização restrita seja pré-requisito para a emancipação social e cultural; Barton (1994), que corrobora as propostas de Giroux (1989) e de Silva e Espósito (1990), trazendo os modelos psicológicos e sociais; neles, aspectos individuais e coletivos têm caráter relevante, já que atividades de leitura e escrita estão vinculadas às estruturas sociais que as moldam, com valores, atitudes, sentimentos e relações sociais e culturais de diferentes comunidades; ainda nesta visão, Kleiman (1995) considera a utilização de diferentes contextos de uso do processo de leitura e escrita, já que nele existe interferência sociocultural; nesta linha de pensamento, Tfouni (2004) põe, no centro desse processo, preocupações políticas e sociais de inclusão e justiça, de modo a contribuir para a libertação do homem e seu desenvolvimento.

Soares (2011), diante dos dois modelos verificados para o processo de Alfabetização e Letramento em Língua Materna, aponta ambos como diretamente interdependentes.

$\mathrm{Na}$ perspectiva do Letramento, percebemos a presença da "alfabetização como ato de libertação" (FREIRE, 1976). Vimos, a partir do pensamento expresso pelos autores aqui abordados, indícios de pensamentos freirianos, como: a necessidade da leitura das entrelinhas, do contexto, das possibilidades de pensamentos e superação que um processo de alfabetização deve proporcionar, e a reflexão sobre o que o homem pode fazer com o conhecimento adquirido neste processo. Em suma, a literacia freiriana pode significar muito mais do que a simples competência para ler e escrever. Pode conduzir à conscientização.

A ideia que trazemos aqui é a de que a possibilidade de inserção do homem no mundo leitor o conduz à liberdade de espírito, à atividade intelectual crítica e autônoma, muito embora não tenhamos controle sobre isso. Nossa posição é a de que, desta forma, os sujeitos podem 
ter maiores oportunidades de acesso ao conhecimento formal e informal, o que os levará a transcender à sua própria realidade.

Considerando as duas visões aqui abordadas, entendemos que uma enfatiza a codificação e decodificação dos símbolos, e a outra, o significado. A primeira proposta pode se inscrever em uma leitura e escrita acrítica e fechada em si mesma, com caráter de finitude. Já a segunda insere-se em um amplo espectro de significações do que se fala, se lê e se escreve, e na qual a codificação e decodificação de símbolos vai se desenvolvendo; isso não é "finito", é inconcluso.

Por esse motivo, dentre as relações estabelecidas, priorizamos as de interdependência entre os processos. Tal interdependência é expressa por Soares (2011) quando afirma que a Alfabetização atual não é ensinada a partir de textos artificialmente construídos para a aquisição de técnicas de leitura e escrita, mas, por meio de atividades de Letramento, de leitura e produção de textos reais, ou seja, de práticas sociais de leitura e de escrita.

Posto isso, apresentamos a seguir os aspectos principais dos processos de Alfabetização e Letramento em Matemática, pautados nas relações estabelecidas com a Língua Materna.

\section{Perspectivas de Alfabetização e Letramento em Matemática: relações com a Língua Materna}

Organizamos esse tópico apresentando, brevemente, nossa compreensão quanto às perspectivas presentes em obras de cada um dos autores: Skovsmose, D’Ambrósio, Danyluk e Fonseca (nesta ordem), atendo-nos aos aspectos convergentes. Consideramos que essas convergências destacam aspectos característicos do que, neste texto, designamos Letramento em Matemática, com base em nossas posições acerca da Língua Materna.

Na perspectiva de Skovsmose $(2001,2007,2008)$ e Skovsmose e Niss (2008), depreendemos que o conhecimento matemático emerge dentro de uma sociedade macro e globalizada, envolvendo diretamente aspectos sociais, políticos e técnicos, indo além da aquisição individual de códigos e da habilidade para calcular e usar técnicas matemáticas formais. Tal ideia afina-se a um processo de Letramento em Matemática ${ }^{5}$ a partir do Letramento em Língua Materna:

Interpretamos nas obras do autor que, sem negar a importância de exercícios para consolidar aprendizagens, enfatiza-se a reflexão em cenários para investigação que convidam os alunos e professores a formularem questões e procurarem explicações para situações referenciadas: na matemática "pura", na semirrealidade (problemas escolares que falseiam a realidade ao tentarem imitá-la), ou na realidade. Em Skovsmose (2001, 2007, 2008), na abordagem inicial à Matemática, lida-se com noções matemáticas, suas aplicações em diferentes contextos e a

\footnotetext{
${ }^{5}$ Skovsmose utiliza termos como Alfabetização Matemática, matemacia, materacia e literacia matemática. Em sua visão, eles se interligam e se complementam. A matemacia, para Skovsmose (2001), precisa ser composta por diferentes competências: matemática, tecnológica e reflexiva. Skovsmose (2007) traz que, cerca de quarenta anos depois de Freire, foi criado o termo "letramento", abrangendo ideias da literacia freiriana. Aqui, adotamos a nomenclatura Letramento Matemático pelas convergências encontradas entre autores da Língua Materna.
} 
reflexão sobre essas aplicações, o que confirma a inserção das ideias do autor na perspectiva do Letramento em Matemática.

Outro aspecto abordado como relevante por Skovsmose (2001) é o papel do diálogo no processo de cooperação investigativa, onde o aluno se posiciona a partir de diferentes vias de comunicação. Nesta abordagem, a utilização e desenvolvimento de projetos são propostas que contribuem para o pensamento crítico e ajudam na constituição do conhecimento em diferentes contextos, favorecendo, assim: a cooperação investigativa, a reflexão e libertação do homem.

Para D’Ambrósio (1986, 1992, 1993a, 1993b, 1997, 1998, 1999, 2001, 2005, 2012), o conhecimento matemático emerge dentro de um grupo ou comunidade, com seus aspectos culturais e sociais subjacentes, sendo estes analisados a partir de uma perspectiva histórica e cultural na sociedade global. Desta forma, suas ideias também se inserem na perspectiva designada, aqui, como Letramento em Matemática ${ }^{6}$, pois vinculam-se primordialmente à reflexão de conhecimentos culturais advindos de comunidades ou grupos sociais.

Nesse processo, o autor prioriza análises críticas e interpretações de um contexto, para a aplicação e o uso de códigos e métodos adequados àquele grupo. Logo, tradição, cultura, reflexão, conscientização e conhecimento matemático estão presentes em todo o processo que, nestes moldes, perpassam toda a vida dos sujeitos aprendentes, sendo de tal forma inconcluso - o que reforça sua inserção na perspectiva do Letramento em Matemática. Nesta perspectiva, as práticas variam de acordo com o local, com o uso específico e dependente da linguagem, da religião e dos valores culturais nos quais o conhecimento se desenvolve e é utilizado. Assim, resgatam-se diferentes ideias e pensamentos matemáticos em seus contextos de uso.

Danyluk (1984, 1991a, 1991b, 1992, 1993, 1994, 2002, 2012) se dedica a crianças, trazendo a fala, a leitura e a escrita da linguagem matemática, aliadas ao sentido e significado do conhecimento como pontos centrais em seu processo de Alfabetização Matemática. Partindo da escuta do que dizem as crianças, elabora e promove atividades envolvendo matemática, para as crianças vivenciarem. Neste sentido, o contexto assume papel relevante, pois, para a autora, a criança consegue compreender e entrar para o mundo da escrita matemática, a partir de situações de uso do conhecimento. Assim, insere-se também na perspectiva do Letramento em Matemática. A autora também acredita que a linguagem matemática a ser lida, interpretada e comunicada é permeada por ideias e ideais da sociedade e da cultura. Logo, fala e escrita vão revelar cultura, tradição e experiências de um grupo ou civilização. Diante disso, um papel significativo será dado ao diálogo e à escuta, pois entende-se que ambos motivam e incentivam o pensamento meditativo e o raciocínio dos alunos. Nessa orientação, o aluno compreende o que lê, escreve e comunica suas compreensões a respeito das primeiras noções de aritmética e geometria. Em sua proposta, a sintática não se sobrepõe à semântica, estando o conhecimento relacionado à sua função e o sentido que dela emana. Isso reforça a pertinência ao Letramento em Matemática.

\footnotetext{
${ }^{6}$ Materacia vem da tradução do termo matheracy. Ele é também utilizado por D’Ambrósio em vários trabalhos sobre etnomatemática com o mesmo significado com que Skovsmose utiliza mathemacy. D’Ambrósio considera a Literacia, a Materacia e Tecnoracia como vertentes que devem compor os processos que designamos, atualmente, Letramento Matemático.
} 
Já Fonseca (2001, 2004a, 2004b, 2005, 2007, 2009) e Fonseca e Cardoso (2005) apresentam a Alfabetização Matemática vinculada à Alfabetização em Língua Materna, como domínio de códigos e símbolos no processo de leitura e escrita. A aquisição da linguagem matemática formal e do registro escrito, no trabalho com noções matemáticas prepondera nesta proposta. Os semânticos e sintáticos no contexto matemático "puro" se revelam, sendo que a autora julga que, nos papéis da escrita numérica e das formas de quantificar, medir etc., estão embutidas formas de uso, objetivos, valores, crenças e atitudes. Porém, a autora propõe que, a partir do domínio de conceitos matemáticos aprendidos na escola, sejam utilizados problemas cotidianos. Desta forma, a estratégia de resolução de problemas é proposta após o domínio de conceitos, o que diferencia esta das demais propostas de Letramento apresentadas neste texto. Pelas características anteriores, interpretamos que Fonseca (2001, 2004a, 2004b, 2005, 2007, 2009) nos traga processos de Alfabetização e de Letramento em Matemática distintos e complementares. Reforça essa interpretação, o fato de a autora propor o trabalho com gêneros textuais, que trazem contextos (incluindo o matemático "puro" e de suas aplicações). Assim, os conhecimentos são diretamente afetados pelas interferências de contextos sociais, políticos, históricos e/ou culturais, econômicos e linguísticos em um processo longo de desenvolvimento que tem parecença com o Letramento em Língua Materna.

Enfim, as obras de três dos autores aqui abordados, na última perspectiva, são permeadas pela busca, cooperação e discussão investigativas, para que o conhecimento seja interpretado, analisado e questionado. O desenvolvimento de pesquisas, a utilização de estratégias de resolução de problemas são algumas das formas apresentadas nas propostas. A autora, em cujas obras enxergamos processos complementares de Alfabetização e Letramento Matemático, contribui com o uso de Gêneros Textuais em sala de aula.

Pelo exposto, podemos considerar que as publicações trazem o domínio de códigos e símbolos, bem como a leitura e escrita como aspectos fundamentais ao processo de Alfabetização Matemática. No entanto, tais aspectos precisam estar diretamente vinculados a variados contextos de aprendizagem e formação: social, cultural, político, econômico etc., não se reduzindo ao matemático "puro", para se atingir o Letramento em Matemática.

Nesta perspectiva, existem diferentes fontes e formas de adaptar a linguagem matemática que pode ser afetada pelo contexto. $\mathrm{O}$ aluno precisa atribuir sentido e imprimir significados a conceitos, propriedades e procedimentos, para utilizá-los na vida, com possibilidades de desenvolvimento e mudança.

Ainda, devem-se considerar as diferentes formas de expressão do conhecimento (oral, escrita etc.), e o professor precisa promover e favorecer o diálogo e a escuta em sala de aula. Oralidade e escrita são importantes formas de expressão do conhecimento, embora não sejam as únicas, e ambas contribuem para a formação conceitual e atitudinal dos alunos.

Nessa perspectiva, os ambientes de aprendizagem assumem papel relevante e, também, a autonomia do aluno, em prol da criatividade, das sínteses e das críticas.

Expostos os processos e destacadas as convergências e complementaridades da Alfabetização e Letramento em Língua Materna e em Matemática, passamos às considerações finais, tecendo implicações para o ensino. 


\section{Considerações finais: fincando estacas nas implicações para a formação e o ensino}

Apesar de termos publicações que consideram a possibilidade dos processos e Alfabetização e Letramento em Língua Materna serem tratados de forma distinta e independente (ABUD, 1987; COOK-GUMPERZ, 1991; GIROUX, 1989; KLEIMAN, 1995; TFOUNI, 2004), aqui apontamos que, muitas vezes, a Alfabetização restrita ao domínio dos símbolos, em seus aspectos sintáticos, termina sendo trabalhada, para, depois, o significado ser abordado. Entendemos que, talvez, isso ocorra por uma questão de conveniência, de ênfase ou prioridade. Diante desta realidade, consideramos que é preciso o domínio dos símbolos, mas não se pode, simplesmente, ignorar o significado do que se lê e escreve, na Escola.

A Alfabetização em Matemática pode ter o caráter restrito, quando se considera o domínio de códigos e símbolos, a leitura e a escrita como prioritários, ou quando este se reduz ao contexto matemático "puro". Neste sentido, os aspectos sintáticos são abordados e postos em situação de destaque, como ocorre no modelo de Alfabetização em Língua Materna apontado no parágrafo anterior.

Nessa visão restrita, o significado em vários contextos, pode vir em um segundo plano ou, até, seguir uma proposta hierárquica de trabalho nas salas de aulas das escolas. Desta forma, os saberes escolares se sobrepõem aos saberes discentes, impedindo ou dificultando o trabalho a partir desses últimos. Pode-se tratar a classe de forma homogênea, desrespeitando as características individuais e de grupo. Logo, nesta visão, a escola e o professor podem assumir o papel de exclusores. Nela, abre-se espaço para limitar o sujeito aprendente, alijando-o de oportunidades de formação geral enredada a conhecimentos matemáticos amplos. A escola e o professor podem se reduzir a aspectos sintáticos no trabalho interno à matemática, sem atingir a semântica.

Dentro desta visão, tampouco se prioriza uma abordagem que possibilite a geração do pensamento reflexivo, crítico, analítico, investigativo ou cooperativo, no sentido amplo. Assim, entendemos que ela favorece uma atitude sem perspectivas transformadoras da realidade individual e coletiva.

Porém, entendemos que a Alfabetização em Matemática pode ir muito além desta visão, quando se considera o que aqui designamos de Letramento em Matemática, por comparação com perspectivas da Língua Materna.

Nesse último processo, no trabalho tramado em contextos variados: histórico-cultural, social, matemático etc., são considerados os aspectos sintáticos nas diversas representações matemáticas, ao mesmo tempo que os aspectos semânticos advindos dos diversos contextos. Há que se abarcar significados atribuídos a conceitos, propriedades ou procedimentos em diversos contextos, bem como possíveis propósitos de produções envolvendo a matemática e consequências de suas veiculações. Além disso, produzem-se discursos, registros e escritas para expressar ideias, pensamentos e raciocínios.

Tuttle (2005, p. 25) acredita que escrever em matemática ajuda o aluno a pensar. Conforme vimos em Tfouni (2004) e Goody e Watt (1990), o processo de escrita está diretamente relacionado ao desenvolvimento do raciocínio. Mas, não é apenas este processo que tem tal potencialidade, o discurso oral em sala de aula também tem, como apontado por Scribner e Cole (1981). 
Entendemos que trabalhar a comunicação em sala de aula, no processo de Letramento em Língua Materna e em Matemática, é aspecto fundamental para a formação dos educandos. Esse processo de comunicação pode variar, mas deve existir.

O discurso oral pode ser uma porta aberta para a leitura e a escrita (LOPES; COSTA, 2009 apud SARDINHA; AZEVEDO, 2009, p. 46), quando consideramos que as crianças expressam, inicialmente, seu conhecimento por meio da fala; e, ainda, tal discurso pode transformar a relação professor-aluno, aluno-aluno e conhecimento-aluno. Nesta proposta, o ambiente escolar é fundamental quando favorece o desenvolvimento, comunicação, socialização, reestruturação e compartilhamento de ideias matemáticas. É neste processo que os alunos vão se apropriando de novos vocabulários e de novos significados matemáticos. O procedimento de escrever permite que eles tenham tempo para pensar, processar seus raciocínios, corrigir, rever o que escrevem e reestruturar a escrita (NACARATO; LOPES, 2009). Logo, permite o desenvolvimento de um processo reflexivo analítico, sintético e crítico.

De acordo com Freitas e Fiorentini (2007), é também no processo de comunicação que o aprendiz entende o sentido do que está sendo ensinado, e isso o ajuda no desenvolvimento, compreensão e significação dos conceitos e procedimentos matemáticos.

Os processos de comunicação nas aulas de Matemática trazem fortes indícios das interpretações que estão sendo feitas pelos alunos. Em prol da inclusão, o professor pode usá-las para refletir e agir em função delas.

Nessa perspectiva, os ambientes de aprendizagem assumem papel relevante. Eles podem ser internos e externos à Escola, sendo, portanto, permeados por influências dos contextos ora mencionados. Assim, o processo de Letramento em Matemática tem caráter reflexivo e de desenvolvimento conceitual.

A autonomia do aluno é importante neste processo, em prol da criatividade no pensar, no fazer, nas análises, interpretações, sínteses e críticas em relação ao conhecimento e aos contextos de onde ele surge e se dá. É preciso ainda que haja compreensão das interpretações nas comunicações de conhecimentos matemáticos.

Soares (2001) pontua que, apesar de o termo Letramento denotar o resultado de uma ação de ensinar a ler e escrever, a preferência do emprego desse termo pode ter decorrido de preocupação aflitiva de disponibilização desses processos a uma parcela da população brasileira à qual são vedadas diversas oportunidades de participação na cultura escrita.

Destarte, reiteramos que a perspectiva do Letramento aqui considerada é preocupada com os processos de aprendizagem e de uso da leitura e escrita com influências sociais, culturais, político-democráticas, econômicas, visando à libertação do homem. Por isso, nesse texto, Letramento não se volta à identificação de competências e habilidades associadas a resultados do ensino formal de apenas uma disciplina escolar.

Ainda, dentro das discussões aqui desenvolvidas, propusemos variadas estratégias de ensino. No entanto, entendemos ser fundamental considerarmos a adequação delas ao que se sabe sobre os educandos e o que se escuta, se lê deles.

Assim, não podemos deixar de lembrar que a incorporação destas estratégias demandam tempo, paciência e reflexões dos alunos, seus pais, professores e gestores escolares, pois pode ser preciso romper com crenças e concepções que esses atores apresentam em relação ao ensino e a aprendizagem de matemática. A proposta requer sair de zonas de conforto e de certezas. Logo, as politícas institucionais devem contemplar o tempo contratual para reflexões conjuntas. 
Nesse sentido, consideramos importante apontarmos que a incorporação dessa perspectiva é e deve continuar sendo baseada em investigações de professores sobre suas aulas e de pesquisadores da Educação Matemática, em contínuo processo de atualização para embasar determinações governamentais.

Entendemos que conhecer os aspectos concernentes à Alfabetização e Letramento em Matemática a partir de todas as publicações aqui usadas, foi essencial, para propormos, aos docentes e aos gestores escolares, estratégias de ensino embasadas.

No entanto, são necessárias outras publicações, sobre os estudos que fizemos, no desenrolar da tese de Maia (2013), voltados aos conteúdos, aos livros didáticos etc., cuja escolha é também de responsabilidade dos sistemas de ensino. Aqui nos dedicamos apenas a um dos fios da rede complexa em que se insere o ensino de matemática, aquele que nos pareceu urgente. Também deixamos para outra publicação certas divergências ou determinados distanciamentos de ideias em obras dos autores aqui priorizados, que podem embasar discussões, mas que consideramos menos urgentes.

Mesmo assim, estamos satisfeitas de indicar alguns resultados de pesquisas a professores e gestores educacionais - os principais protagonistas da vida na escola.

\section{Referências}

ABUD, M. J. Teorias básicas de educação e ensino. São Paulo: Universitária, 1987.

BARTON, D. Literacy: an introduction to the ecology of written language. Oxford: Blackwell, 1994.

BRASIL. Ministério da Educação. Ensino fundamental de 9 anos: orientações gerais. 2. ed. Brasília: SEF, 2004.

Ensino fundamental de 9 anos: passo a passo do processo de implantação. 2. ed. Brasília: SEF, 2009.

COOK-GUMPERZ, J. A construção social da alfabetização. Porto Alegre: Artes Médicas, 1991.

D'AMBROSIO, U. Da realidade à ação: reflexões sobre educação matemática. Campinas: Unicamp, 1986.

. Educação matemática: da teoria à prática. 23. ed. Campinas: Papirus, 2012.

- A educação matemática e a reincorporação da matemática à história e à filosofia.

In: SEMINÁRIO INTERNACIONAL DE EDUCAÇÃO MATEMÁTICA DO RIO DE JANEIRO, 1., 1993. Rio de Janeiro. Anais... Rio de Janeiro: UFRJ, 1993a. 1 CD-ROM.

. Etnomatemática, um elo entre as tradições. Belo Horizonte: Autêntica, 2001.

. Etnomatemática, um programa. Educação Matemática em Revista, Blumenau, v. 1, n. 11 , p. $5-11,1993$ b. 
D’AMBROSIO, U. Literacia e materacia: objetivos da educação fundamental. Pátio: revista pedagógica, Porto Alegre, v. 1, n. 3, p. 22-26, 1998.

. Literacy, matheracy, and technoracy: a trivium for today. Mathematical Thinking and Learning, Philadelphia, v. 1, n. 2, p. 131-153, 1999.

. Reflexões sobre história, filosofia e matemática. Bolema: boletim de educação matemática, Rio Claro, n. 2, p. 42-60, 1992. Número especial.

Sociedade, cultura, matemática e seu ensino. Educação e Pesquisa, São Paulo, v. 31, n. 1, p. 99-120, jan/abr, 2005.

. Tantos povos, tantas matemáticas. Educação, São Paulo, v. 23, n. 199, p. 3-5, 1997.

DANYLUK, O. Alfabetização matemática: o cotidiano da vida escolar. Caxias do Sul: EDUCS, 1991a.

- Alfabetização matemática: as primeiras manifestações da escrita infantil. Porto Alegre: Sulina, 2002.

- Alfabetização matemática: as primeiras noções de matemática. Cadernos de Psicossociologia e Educação, Porto Alegre, n. 1, p. 19-30, 1993.

. O ato de ler o discurso matemático. Leitura: teoria e prática, Campinas, v. 10, n. 18, p. 17-22, dez, 1991b.

. A evolução das operações aritméticas. Rio Claro: UNESP, 1984.

- (Org.). História da educação matemática: escrita e reescrita de histórias. Porto Alegre: Sulina, 2012.

. A matemática, o professor de matemática e o seu ensino. In: RIO GRANDE DO SUL. Secretaria de Estado da Educação. Projeto melhoria da qualidade de ensino. Porto Alegre, 1992. p. 9-16.

- As relações da criança com a alfabetização matemática. Educação Matemática em Revista, Blumenau, n. 2, p. 48-52, 1994.

FONSECA, M. C. F. R. Conceito(s) de numeramento e relações com o letramento. In: LOPES, C. E.; NACARATO, A. M. (Org.). Educação matemática, leitura e escrita: armadilhas, utopias e realidade. Campinas: Mercado de Letras, 2009. p. 56-73.

Discurso, memória e inclusão: reminiscências da matemática escolar de alunos adultos do ensino fundamental. 2001. Tese (Doutorado em Educação) - Faculdade de Educação, Universidade Estadual de Campinas, Campinas, 2001.

- A educação matemática e a ampliação das demandas de leitura e escrita da população brasileira. In: . Letramento no Brasil: habilidades matemáticas. São Paulo: Global, 2004a. p. 11-28.

Estudos sobre numeramento: conceitos e indagações. In: CONGRESSO DE LEITURA DO BRASIL, 8., 2005. Caderno de Resumos 1... Campinas: ALB, 2005. p. 47-66. 
FONSECA, M. C. F. R. (Org). Letramento no Brasil: habilidades matemáticas. São Paulo: Global, 2004b.

. Sobre a adoção do conceito de numeramento no desenvolvimento de pesquisas e práticas pedagógicas na educação matemática de jovens e adultos. ENCONTRO NACIONAL DE EDUCAÇÃO MATEMÁTICA, 9., 2007, Belo Horizonte. Anais... Belo Horizonte, 2007. 1 CD-ROM.

FONSECA, M. C. F. R.; CARDOSO, C. A. Educação matemática e letramento: textos para ensinar matemática, matemática para ler o texto. In: NACARATO, A. M.; LOPES, C. E. (Org.). Escritas e leituras na educação matemática. Belo Horizonte: Autêntica, 2005. p. 63-76.

FREIRE, P. Ação cultural para a liberdade e outros escritos. Rio de Janeiro: Paz e Terra, 1976.

FREITAS, M. T. M.; FIORENTINI, D. As possibilidades formativas e investigativas da narrativa em educação matemática. Horizontes, Bragança Paulista, v. 25, n. 1, p. 63-71, jan./ jul. 2007.

GIROUX, H. A. Schooling for democracy: critical pedagogy in the modern age. London: Routledge, 1989.

GOODY, J.; WATT, I. The consequences of literacy, in language and social context. In:

GIGLIOLI, P. P. (Ed.). Language and social context: selected readings. Harmondsworth: Penguin, 1990. p. 311-357.

KLEIMAN, A. B. (Org.). Os significados do letramento: uma nova perspectiva sobre a prática social da escrita. Campinas: Mercado de Letras, 1995.

MAIA, M. G. B. Alfabetização matemática: aspectos concernentes ao processo na perspectiva de publicações brasileiras. 2013. Tese (Doutorado em Educação Matemática) Pontifícia Universidade Católica de São Paulo, São Paulo, 2013.

NACARATO, A. M.; LOPES, C. E. Práticas de leitura e escrita em educação matemática: tendências e perspectivas a partir do Seminário de Educação Matemática no COLE. In: LOPES, C. E.; NACARATO, A. M. (Org.). Educação matemática, leitura e escrita: armadilhas, utopias e realidade. Campinas: Mercado de Letras, 2009. p. 38-54.

SARDINHA, F. P.; AZEVEDO, F. J. F. Histórias com problemas e a sua ligação à promoção da numeracia e da literacia no 1. ${ }^{\circ}$ ciclo do ensino básico. 2011. 434 f. Tese (Doutorado em Estudos da Criança) - Instituto de Educação, Universidade do Minho, [Braga], 2011.

SCRIBNER, S.; COLE, M. The psychology of literacy. Cambridge: Harvard University Press, 1981.

SILVA, N. R.; ESPOSITO, Y. L. Analfabetismo e subescolarização: ainda um desafio. São Paulo: Cortez, 1990. 
SKOVSMOSE, O. Desafios da reflexão em educação matemática crítica. Campinas: Papirus, 2008.

2007.

. Educação crítica: incerteza, matemática, responsabilidade. São Paulo, Cortez,

. Educação matemática crítica: a questão da democracia. Campinas: Papirus, 2001;

SKOVSMOSE, O.; NISS, M. Critical mathematics education for the future. In: NISS, M.

(Ed.). Proceedings of the 10th International Congress on Mathematical Education.

Aalborg: Roskilde University University, 2008. p. 1-19.

SOARES, M. Alfabetização e letramento. 6. ed. São Paulo: Contexto, 2011.

Letramento: um tema em três gêneros. Belo Horizonte: Autêntica, 2001.

STREET, B. V. Literacy in theory and practice. Cambridge: Cambridge University Press, 1984.

TFOUNI, L. V. Letramento e alfabetização. 6. ed. São Paulo: Cortez, 2004.

TUTTLE, C. L. Writing in the mathematics classroom. In: KENNEY, J. M.; HANCEWICZ, E.; HEUER, L. Literacy strategies for improving mathematics instruction. Alexandria: Association for Supervision and Curriculum Development, 2005. p. 24-50. 